\title{
Influence of the Sputtering Technique and Thermal Annealing on YSZ Thin Films for Oxygen Sensing Applications
}

\author{
Emilio Paz Alpuche ${ }^{1,2, * \mathbb{C}}$, Pascal Gröger ${ }^{2}$, Xuetao Wang ${ }^{1}{ }^{\mathbb{D}}$, Thomas Kroyer $^{1}$ and Stefanos Fasoulas ${ }^{2}$ \\ 1 Fraunhofer Institute for Solar Energy Systems, Heidenhofstraße 2, 79110 Freiburg, Germany; \\ xuetao.wang@namlab.com (X.W.); thomas.kroyer@ise.fraunhofer.de (T.K.) \\ 2 Institute of Space Systems, University of Stuttgart, Pfaffenwaldring 29, 70569 Stuttgart, Germany; \\ pgroeger@irs.uni-stuttgart.de (P.G.); fasoulas@irs.uni-stuttgart.de (S.F.) \\ * Correspondence: emilio.paz.alpuche@ise-extern.fraunhofer.de
}

Citation: Paz Alpuche, E.; Gröger, P.; Wang, X.; Kroyer, T.; Fasoulas, S. Influence of the Sputtering Technique and Thermal Annealing on YSZ Thin Films for Oxygen Sensing Applications. Coatings 2021, 11, 1165. https://doi.org/10.3390/coatings 11101165

Academic Editor: Susana Sério

Received: 27 July 2021

Accepted: 22 September 2021

Published: 27 September 2021

Publisher's Note: MDPI stays neutral with regard to jurisdictional claims in published maps and institutional affiliations.

Copyright: (c) 2021 by the authors. Licensee MDPI, Basel, Switzerland. This article is an open access article distributed under the terms and conditions of the Creative Commons Attribution (CC BY) license (https:/ / creativecommons.org/licenses/by/ $4.0 /)$.

\begin{abstract}
Yttria-stabilized zirconia (YSZ) thin films were deposited using direct current (reactive and metallic) and radio frequency magnetron sputtering. The effect of the deposition technique and annealing treatment on the microstructure and crystallinity of the thin films was assessed. Using the films produced in this work, oxygen gas sensors were built and their performance under vacuum conditions was evaluated. All the films exhibited a cubic crystalline structure after a post-deposition thermal treatment, regardless of the sputtering technique. When the annealing treatment surpassed $1000{ }^{\circ} \mathrm{C}$, impurities were detected on the thin film surface. The oxygen gas sensors employing the reactive and oxide-sputtered YSZ thin films displayed a proportional increase in the sensor current as the oxygen partial pressure was increased in the evaluated pressure range $\left(5 \times 10^{-6}\right.$ to $2 \times 10^{-3}$ mbar). The sensors which employed the metallic-deposited YSZ films suffered from electronic conductivity at low partial pressures.
\end{abstract}

Keywords: yttria-stabilized zirconia; YSZ; sputtering; oxygen sensor; solid-state electrolyte

\section{Introduction}

Yttria-stabilized zirconia (YSZ) is widely employed in technical applications such as thermal barrier coatings [1-3], solid oxide fuel cells (SOFC) [4-7], and oxygen gas sensors $[8,9]$. Besides its high thermal and mechanical stability, the ionic conductivity of YSZ plays a major role in most of its applications. Zirconia-based oxygen gas sensors can be employed for monitoring the oxygen content in a gas flow or to optimize combustion processes [8]. With the development of microfabrication technologies in the past decades, miniaturized sensors with low power consumption, high sensitivity, high durability, and quick response time have become the focus of today's research [10]. Therefore, the deposition of thin films with high ionic conductivity is necessary to meet these requirements.

Different technologies are readily available for the fabrication of YSZ thin films, i.e., sol-gel processes [11,12], chemical vapor deposition (CVD) [6,13], and physical vapor deposition (PVD) [14-16]. Magnetron sputtering is a widespread PVD technology used to produce uniform thin layers from a few nanometers up to a few micrometers. Even though high-quality films can be deposited at room temperature, a post-deposition thermal treatment can enhance the ionic conductivity by improving the crystallinity and density of the film $[3,5,17,18]$.

In a typical direct current (DC) sputtering deposition, an electrical conducting target and an inert gas, commonly a metal target and argon, are employed to deposit thin films. If a mixture of an inert and reactive gas (e.g., oxygen) is employed, then a compound material is formed (e.g., oxide). This is also known as reactive sputtering. As the amount of reactive gas is increased, the deposition rate decreases, and the process becomes unstable due to the formation of a compound material on the target surface commonly referred to as "target poisoning". Therefore, substoichiometric oxides are occasionally deposited through 
reactive sputtering due to its lower complexity. During this work, reactive sputtering refers to the deposition of substoichiometric oxide films. Meanwhile, radio frequency (RF) sputtering allows the usage of a dielectric material as the target and the deposition of stoichiometric oxide films is possible. RF sputtering has lower deposition rates and higher costs in comparison to DC sputtering.

Since the end of the 1970s, oxygen (lambda) sensors based on a zirconia solid-state electrolyte have been employed to optimize the fuel combustion process on automobiles. Potentiometric sensors such as the lambda sensor measure a voltage between the analyzed gas and the reference gas, typically air, in order to calculate the oxygen concentration [19]. The need of a reference gas hinders the usage of potentiometric sensors "in situ" for vacuum applications. Contrary to the potentiometric principle, amperometric sensors are able to determine the oxygen concentration of gases without the need of a reference gas. By intentionally applying a voltage between the electrodes, a current proportional to the oxygen concentration can be measured [20]. In order to ensure this proportionality, the sensors need to operate under diffusion-limited conditions [8]. This can be achieved by using a porous thin film on top of the sensing electrode which acts as a diffusion barrier.

Götsch et al. deposited YSZ thin films with 3 to 40 mol.\% yttria $\left(\mathrm{Y}_{2} \mathrm{O}_{3}\right)$ concentrations through dc ion beam sputtering [21]. The films with an yttria concentration from 8 to $20 \mathrm{~mol} . \%$ exhibited a cubic crystal structure. Rusli et al. demonstrated that the crystalline structure and morphology of rf-sputtered 8 mol.\% yttria-stabilized zirconia (8YSZ) thin films can be tailored through a post-deposition annealing treatment from 380 to $600{ }^{\circ} \mathrm{C}[22,23]$. Smeacetto et al. reported to have deposited 8YSZ thin films of 100 and $200 \mathrm{~nm}$ thickness with high ionic conductivity through rf-sputtering for SOFC's purposes [24].

In this work, DC (reactive and metallic) and RF (oxide) sputtering techniques were used to deposit yttria-stabilized zirconia (YSZ) thin films. The effect of a post-deposition thermal treatment from 600 to $1200{ }^{\circ} \mathrm{C}$ on the crystal structure, morphology, and elemental composition of the thin films was evaluated. Finally, the YSZ thin films were used as a solid-state electrolyte in amperometric oxygen gas sensors fabricated by means of a lift-off photolithography process. The gas sensing performance for low oxygen partial pressures under vacuum conditions was investigated using a self-built testing chamber and data acquisition program at the Institute of Space Systems (IRS) of the University of Stuttgart.

\section{Materials and Methods}

In this work, $100 \mathrm{~nm}$ thin films of yttria-stabilized zirconia (YSZ) were deposited using DC and RF magnetron sputtering at the Fraunhofer Institute for Solar Energy Systems in Freiburg, Germany. Both DC deposition processes, reactive and metallic, were conducted in a custom-made sputtering machine (Interpane E\&B, Lauenförde, Germany) using a 80:20 at.\% Zr:Y metallic alloy target (99.99\% purity) from Sindlhauser Materials. The RF depositions were carried out in an FHR.Star.100-TetraCo sputtering machine (FHR Anlagenbau, Ottendorf-Okrilla, Germany), using a 90:10 mol.\% $\mathrm{ZrO}_{2}: \mathrm{Y}_{2} \mathrm{O}_{3}$ oxide target ( $99.95 \%$ purity). The thin films were sputtered using argon as sputtering gas at a sputtering pressure of about $1.3 \times 10^{-3}$ mbar and a base vacuum pressure of $1 \times 10^{-5} \mathrm{mbar}$. For the reactive-sputtered films, an additional oxygen flow was employed. The deposition parameters are shown in Table 1.

Table 1. Sputtering deposition parameters.

\begin{tabular}{ccccc}
\hline Power Source & Mode & $\begin{array}{c}\text { Sputtering } \\
\text { Power Density } \\
\left(\mathbf{w} / \mathbf{c m}^{\mathbf{2}}\right)\end{array}$ & Ar Flow (sscm) & $\mathbf{O}_{\mathbf{2}}$ Flow (sscm) \\
\hline direct current & metallic & 1.27 & 58 & 0 \\
direct current & reactive & 2.08 & 58 & 15 \\
radio frequency & oxide & 5.09 & 28 & 0 \\
\hline
\end{tabular}


The YSZ thin films were then employed as a solid-state electrolyte for fabricating amperometric oxygen sensors. The sensors produced in this work were manufactured completely using thin films deposited via magnetron sputtering. The electrode and the microheater were deposited by (metallic) DC sputtering and their corresponding barrier layers using reactive DC sputtering. Polycrystalline aluminum oxide substrates from Kyocera (model: A493, purity: 99.6\%) were used for the sensor fabrication and characterization of the thin films. The thin film patterns were achieved by a lift-off photolithography process using the negative photoresists AZ nLoF 2035 and 2070 (MicroChemicals, Ulm, Germany) and an EVG mask aligner model 6200 MA (EV Group, Sankt Florian am Inn, Austria).

A schematical setup of the YSZ-based $\mathrm{O}_{2}$-sensor is illustrated in Figure 1. The dimensions of a single sensor were $3.5 \times 0.5 \times 23 \mathrm{~mm}$ (width $\times$ depth $\times$ height). The electrolyte was sputtered and annealed before the deposition of the additional layers. To improve the adhesion between the platinum layers and the $\mathrm{Al}_{2} \mathrm{O}_{3}$ substrate, a $10 \mathrm{~nm}$ platinum oxide adhesion layer was used between the electrode or the heater and the substrate. Likewise, a barrier layer was deposited on top of both platinum films (electrode and microheater) to avoid the rapid agglomeration of the films and to guarantee the diffusion-limited principle of the amperometric sensor. The YSZ films were deposited only under and above the interdigitated working electrode to avoid short circuits and signal distortion during the sensor operation.

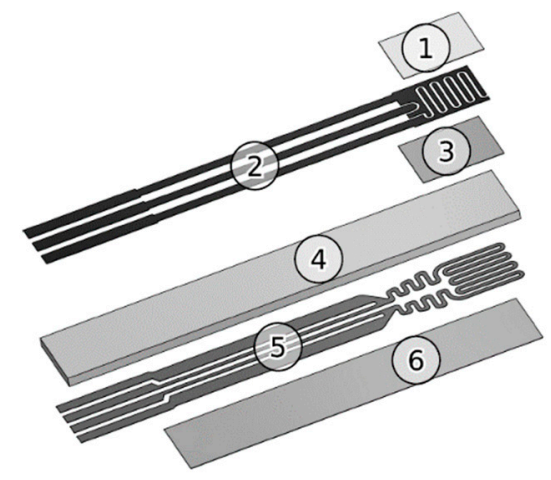

1. Electrode barrier layer $(\mathrm{YSZ}-25 \mathrm{~nm})$

2. Electrode $(\mathrm{Pt}-435 \mathrm{~nm})$

3. Electrolyte $(\mathrm{YSZ}-100 \mathrm{~nm})$

4. Substrate $\left(\mathrm{Al}_{2} \mathrm{O}_{3}-500 \mu \mathrm{m}\right)$

5. Microheater $(\mathrm{Pt}-1135 \mathrm{~nm})$

6. Microheater barrier layer $\left(\mathrm{Al}_{2} \mathrm{O}_{3}-635 \mathrm{~nm}\right)$

Figure 1. Schematic sensor setup and film thickness, adapted from [25].

The crystallinity of the films was characterized using grazing incidence $X$-ray diffraction (GIXD) in a Philips X'Pert MRD system (Malvern Panalytical, Malvern, England) equipped with a $\mathrm{CuK} \alpha \mathrm{X}$-ray source. The characterization of the microstructure and chemical composition was examined using a scanning electron microscope (SEM) model FE-SEM S-4700 (Hitachi, Tokyo, Japan) and a Dimension Edge Atomic Force Microscope (AFM) (Bruker, Billerica, MA, USA). The elemental composition was analyzed through X-ray photoelectron spectroscopy (XPS) using a PHI Quantera II (Physical Electronics, Chanhassen, MN, USA). The film thickness was measured using a Dektak $6 \mathrm{M}$ profilometer (Veeco Instruments, New York, NY, USA). These characterization techniques were employed on plain YSZ thin films sputtered on pristine alumina substrates, without any further thin films or microstructures.

Due to the potential application of the sensors in space systems and in industrial vacuum coating processes, the characterization was performed under vacuum conditions. The developed oxygen gas sensor prototypes were investigated in a custom-made system shown in Figure 2. The sensors were mounted on a holder made of PEEK polymer, where the sensor is strained using two screws and contacted with gold-coated wires. The PEEK polymer is reported to be thermally stable up to $575^{\circ} \mathrm{C}$ [26]. No sign of thermal decomposition during the sensor operation was observed. The data acquisition and sensor operation were accomplished through a home-made electronic system. The test chamber was evacuated to a base pressure of ca. $1 \times 10^{-7}$ mbar using the combination of a rotary and a turbomolecular pump models DUO10M/TMU521YP (Pfeiffer Vacuum, Asslar, Germany). The total pressure inside the chamber was measured using a wide-range vacuum gauge 
model ATMION (JEVATEC, Jena, Germany). Gas flow rates were regulated by a mass flow controller model MF1 Compact (MKS Instruments, Andover, MA, USA). For the sensor characterization presented in this work, after achieving the base pressure of $1 \times 10^{-7} \mathrm{mbar}$ in the chamber, a flow of synthetic gas $\left(20 \% \mathrm{O}_{2}, 80 \% \mathrm{~N}_{2}\right)$ was used to achieve the desired total pressure. The oxygen partial pressure $\left(p_{\mathrm{O}_{2}}\right)$ was set to be $20 \%$ of the total pressure. The sensor current was recorded while varying the oxygen partial pressure every $5 \mathrm{~min}$ in a cyclic manner for a total of ca. $45 \mathrm{~h}$. A cycle consisted of 9 increasing and 9 decreasing steps from $5 \times 10^{-6}$ to $2 \times 10^{-3}$ mbar. During the characterization, the sensors were heated to ca. $600{ }^{\circ} \mathrm{C}$ using the platinum resistance microheater on the back side. The operation of the microheater is described in [25]. This temperature was chosen as a trade-off between the YSZ ionic conductivity and the platinum stability.

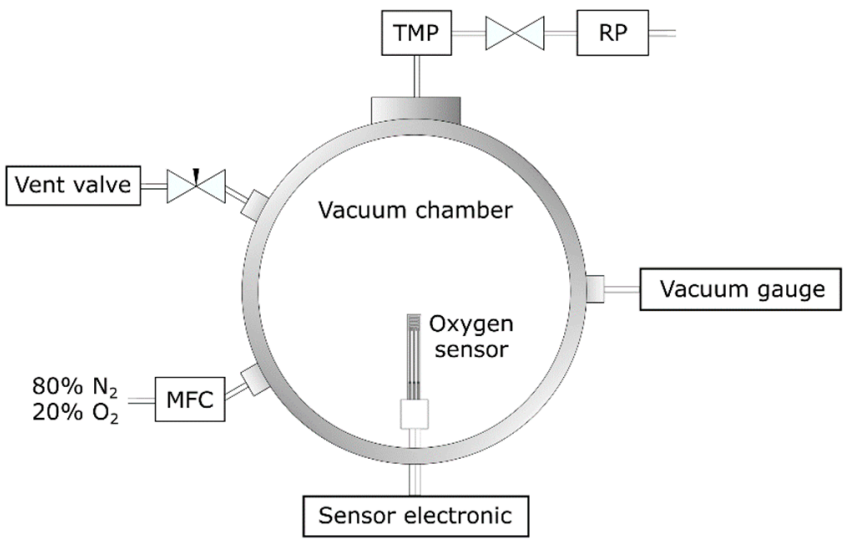

(a)

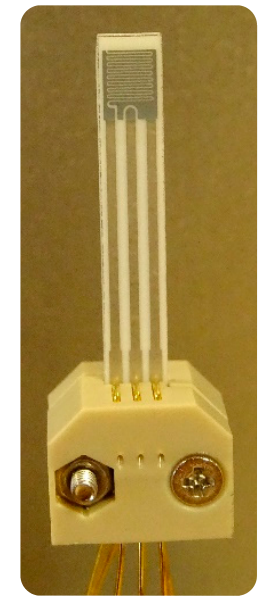

(b)

Figure 2. (a) Schematic diagram of the vacuum chamber for sensor characterization; (b) sensor mounted on the PEEK-adapter and contacted with the gold-coated wires.

\section{Results and Discussion}

\subsection{Crystallinity}

The YSZ thin films were deposited at room temperature followed by an annealing process in air for $4 \mathrm{~h}$ in a furnace at temperatures ranging from 600 to $1200{ }^{\circ} \mathrm{C}$. The X-ray diffraction of the YSZ films as deposited and after annealing are shown in Figure 3. In Figure $3 \mathrm{a}, \mathrm{b}$, the metallic and reactive-sputtered films are amorphous after deposition, only peaks corresponding to the $\mathrm{Al}_{2} \mathrm{O}_{3}$ substrate can be observed, and no reflections belonging to the cubic zirconia phase were identified. In Figure $3 c$, the cubic phase can be observed in the rf-sputtered films directly after deposition. After the heat treatment at $600{ }^{\circ} \mathrm{C}$, all films displayed the desired cubic phase regardless of the deposition technique. The cubic phase was identified using the PDF Card No. 01-082-1246 from the ICDD Database. No other crystal phase was identified, even after high temperature post-deposition treatment.

The grain size of the YSZ thin films was calculated using the Scherrer equation described in [27]:

$$
D_{\text {mean }}=\frac{K \lambda}{\beta \cos \theta}
$$

where $K$ is the crystallite shape factor (in this work $K=0.94$ ), $\lambda$ is the X-ray wavelength, $\beta$ is the full width at half maximum (FWHM) of the (111) reflection located at approximately $2 \theta=30^{\circ}$, and $\theta$ is the diffraction angle. The results are summarized in Table 2. The grain size of the DC-metallic and RF-oxide sputtered films increased considerably from approximately $11-13$ to $29-32 \mathrm{~nm}$ as the annealing temperature was raised from 600 to $1200{ }^{\circ} \mathrm{C}$. Meanwhile, the grain size of the DC-reactive sputtered YSZ films did not change significantly after the heat treatment, i.e., from 27 to $29 \mathrm{~nm}$. After annealing at $1200{ }^{\circ} \mathrm{C}$, the grain sizes of the three different sputtering variations are approximately the same. 


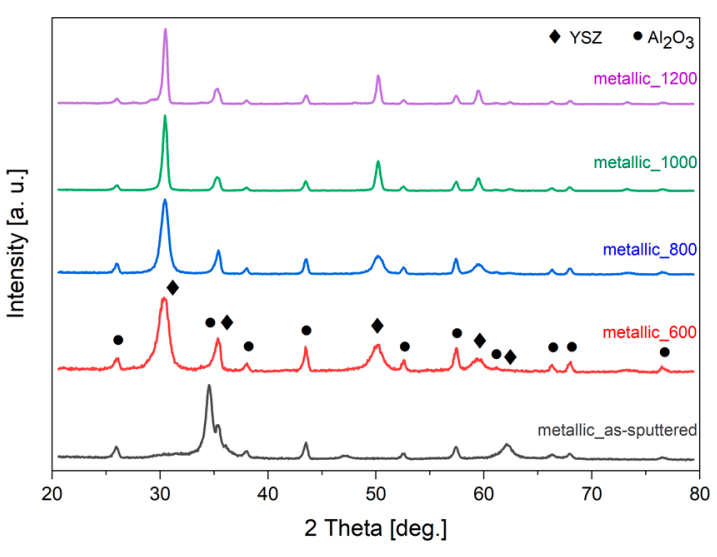

(a)

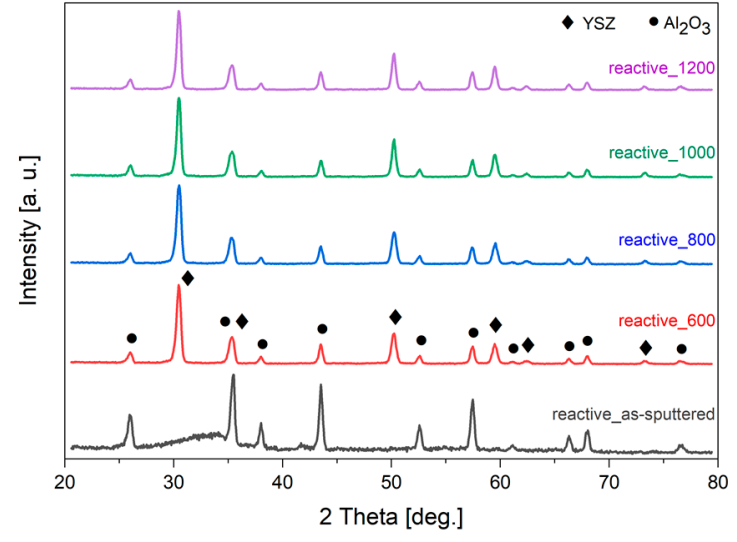

(b)

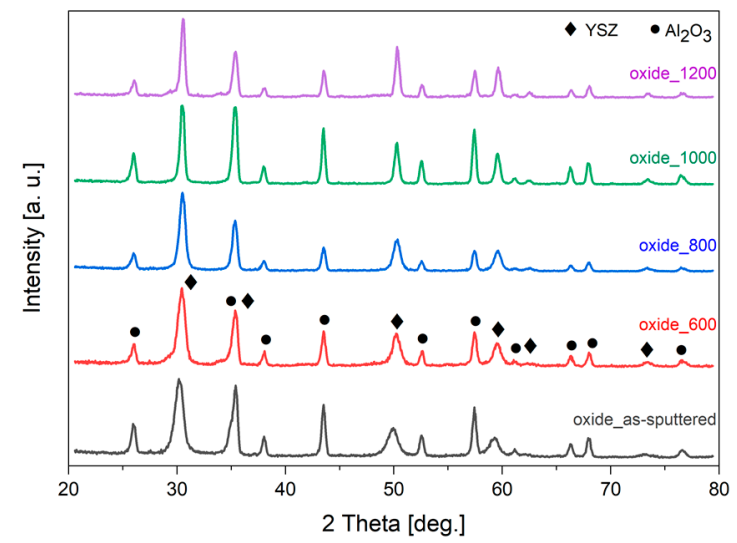

(c)

Figure 3. GIXRD of the sputtered 10YSZ films before and after the annealing treatment: (a) dc-metallic; (b) dc-reactive; and (c) rf-oxide. The reflections belonging to the $\mathrm{Al}_{2} \mathrm{O}_{3}$ substrate and the $\mathrm{YSZ}$ are marked by $(\bullet)$ and $(\diamond)$, respectively.

Table 2. Calculated grain size in nm using the Scherrer equation and the (111) reflection.

\begin{tabular}{ccccc}
\hline & $\mathbf{6 0 0}{ }^{\circ} \mathbf{C}$ & $\mathbf{8 0 0}{ }^{\circ} \mathbf{C}$ & $\mathbf{1 0 0 0}^{\circ} \mathbf{C}$ & $\mathbf{1 2 0 0}^{\circ} \mathbf{C}$ \\
\hline DC-metallic & 11 & 13 & 26 & 32 \\
DC-reactive & 27 & 26 & 29 & 29 \\
RF-oxide & 13 & 18 & 27 & 29 \\
\hline
\end{tabular}

\subsection{Thin Film Morphology}

In Figure 4 , the SEM images of the sputtered films after the annealing treatment at 600 and $1200{ }^{\circ} \mathrm{C}$ are shown. At $600{ }^{\circ} \mathrm{C}$, only the large grains of the polycrystalline alumina substrate can be observed. The DC-metallic and DC-reactive YSZ films were subsequently oxidized after deposition by the thermal treatment from their original metallic and substoichiometric oxide condition. In Figure 4a, the DC-metallic film is the only sample with macroscopic cracks after annealing, probably caused by the large volume change and thermal stresses during oxidation. Voids are visible in all samples, especially at the grain boundaries of the substrate.

The surface roughness was analyzed through AFM measurements, and some results are shown in Figure 5. The high surface roughness $(\mathrm{Ra}=0.05-0.08 \mu \mathrm{m}$, according to the supplier) of the substrate (Figure 5a) hinders a quantitative analysis of the surface roughness evolution as the annealing temperature is raised. 

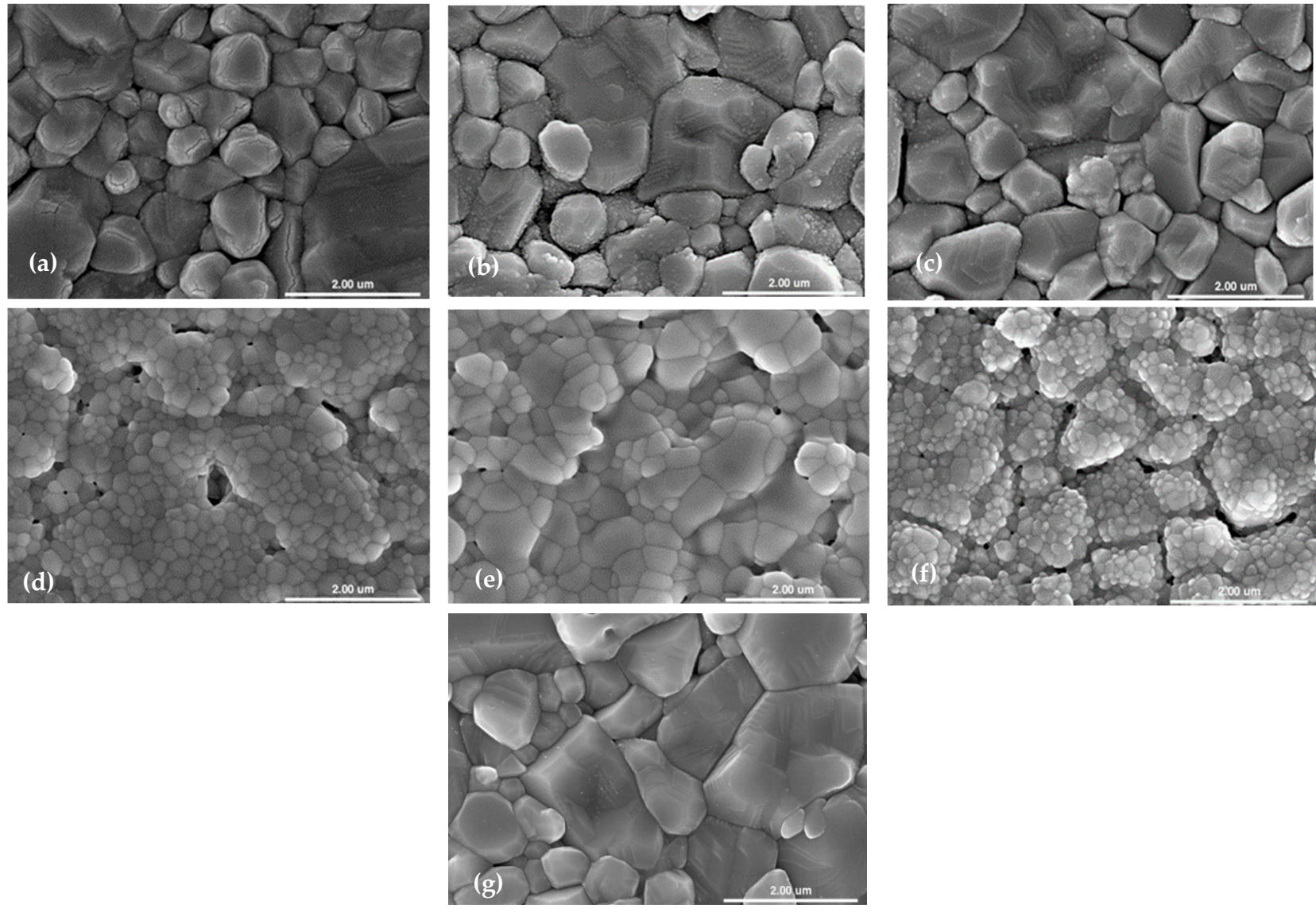

Figure 4. SEM images of the sputtered YSZ films after the thermal annealing process at 600 (above) and $1200{ }^{\circ} \mathrm{C}$ (below): (a,d) DC-metallic; (b,e) DC-reactive; and (c,f) RF-oxide. In (g) the pristine $\mathrm{Al}_{2} \mathrm{O}_{3}$ polycrystalline substrate is shown for comparison.

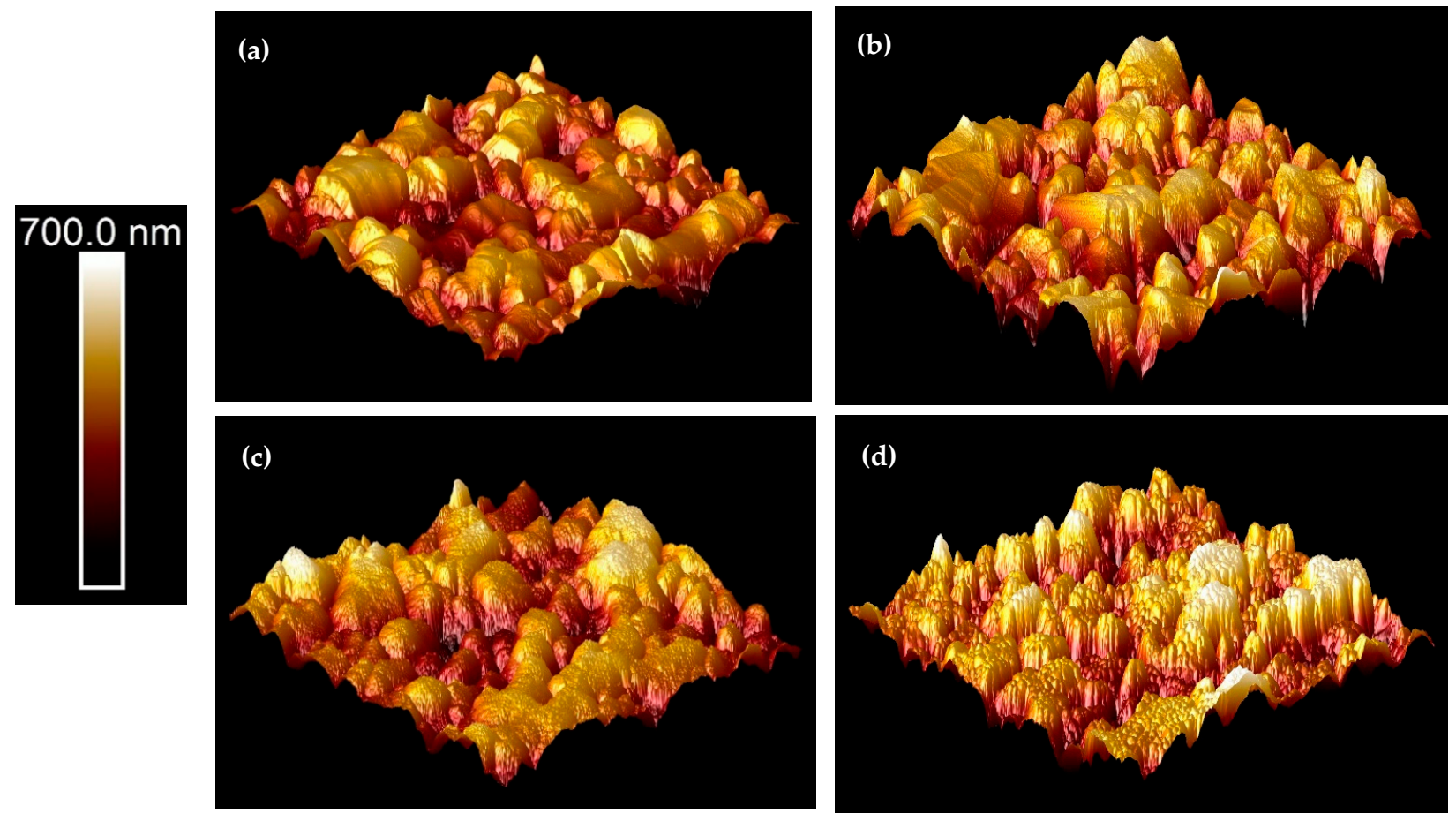

Figure 5. Surface roughness evolution measured by AFM: of the (a) $\mathrm{Al}_{2} \mathrm{O}_{3}$ substrate; (b) RF_800; (c) RF_1000; and (d) RF_1200 samples. The color scale on the left side represents the surface height. 
In agreement with the XRD results, it can be noticed from Figures 4 and 5 that at $1000{ }^{\circ} \mathrm{C}$ a significant grain growth occurs leading to the formation of small YSZ particles on top of the large $\mathrm{Al}_{2} \mathrm{O}_{3}$-substrate grains. After annealing at $1200{ }^{\circ} \mathrm{C}$, grain growth continues, and highly crystalline YSZ films are formed. Nevertheless, the effect of the polycrystalline substrate on the microstructure and grain growth of the YSZ films cannot be neglected.

\subsection{Elemental Analysis}

The migration of material impurities is a main concern when annealing at high temperatures. The diffusion of impurities to the surface or into the grain boundaries of the YSZ can deteriorate the ion conductivity of the thin films [28,29]. Likewise, several authors report the segregation of yttria to the film surface [30,31]. Therefore, the RF-oxide deposited samples were analyzed using XPS with depth-profiling to determine the yttria content throughout the thin films and to account for possible impurities.

The XPS surface composition of selected YSZ thin films are summarized in Table 3. The yttria content in mol.\% is calculated using the procedure described by Götsch et al. [21]. The yttria content of the films differ depending on the sputtering technique. The surface composition of all films deviated from the desired $10 \mathrm{Y}_{2} \mathrm{O}_{3}$ mol.\%. Since the DC-sputtered samples are not fully oxidized after deposition, the surface compositions after annealing at $600{ }^{\circ} \mathrm{C}$ were taken as a reference when calculating the $\mathrm{Y}_{2} \mathrm{O}_{3}$ content. The samples sputtered with a metallic target (DC-metallic and DC-reactive) presented a higher yttria content than expected, 11.7 and 16.1 at.\%, respectively. The yttria surface enrichment could be due to the high mobility of the metallic yttrium atoms during the oxidation process. Additionally, silver cross-contamination (0.3 at.\%) was measured in the DC-metallic sample.

Table 3. XPS surface survey of selected YSZ thin films. The concentration is expressed in at.\%, unless otherwise stated.

\begin{tabular}{ccccccccc}
\hline Sample & $\mathbf{C}$ & $\mathbf{O}$ & $\mathbf{A l}$ & $\mathbf{S i}$ & $\mathbf{A g}$ & $\mathbf{Z r}$ & $\mathbf{Y}$ & $\begin{array}{c}\mathbf{Y}_{\mathbf{2}} \mathbf{O}_{\mathbf{3}} \\
\text { (mol.\%) }\end{array}$ \\
\hline DC-reactive_600 & 19.9 & 54.9 & 0 & 0 & 0 & 20.0 & 5.3 & 11.7 \\
DC-metallic_600 & 22.6 & 52.7 & 0 & 0 & 0.3 & 17.7 & 6.8 & 16.1 \\
RF-oxide_as-sputtered & 26.1 & 51.0 & 0 & 0 & 0 & 19.2 & 3.7 & 8.8 \\
RF-oxide_600 & 22.4 & 52.9 & 0 & 0 & 0 & 20.7 & 3.9 & 8.6 \\
RF-oxide_800 & 38.9 & 42.0 & 0 & 0 & 0 & 15.5 & 3.0 & 8.8 \\
RF-oxide_1000 & 21.9 & 53.9 & 1.1 & 1.8 & 0 & 17.6 & 3.4 & 8.8 \\
RF-oxide_1200 & 19.4 & 54.8 & 1.7 & 4.4 & 0 & 16.4 & 3.3 & 9.1 \\
\hline
\end{tabular}

On the contrary, the RF-oxide samples deposited from a fully ceramic target displayed a lower but constant yttria surface content, ranging from 8.6 to $9.1 \mathrm{~mol} \%$, despite the heat treatment.

The diffusion of aluminum and silicon to the surface was first detected after annealing the samples at $1000{ }^{\circ} \mathrm{C}$. By increasing the annealing temperature to $1200{ }^{\circ} \mathrm{C}$, the surface diffusion of impurities became more pronounced, reaching a concentration of 1.7 at. $\% \mathrm{Al}$ and 4.4 at.\% Si. In Figure 6, the XPS surface survey spectrum of the rf-sputtered YSZ films before the thermal treatment is shown. The XPS depth-profiling of the RF-sputtered sample after post-annealing at $1200{ }^{\circ} \mathrm{C}$ is also shown in Figure 6. Aluminum and silicon atoms were only detected close to the surface, less than $8 \mathrm{~nm}$ depth. After etching for $10 \mathrm{~min}$, the alumina substrate is reached. 


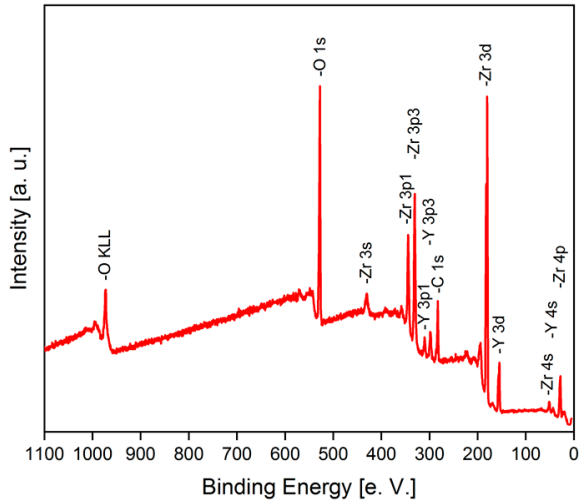

(a)

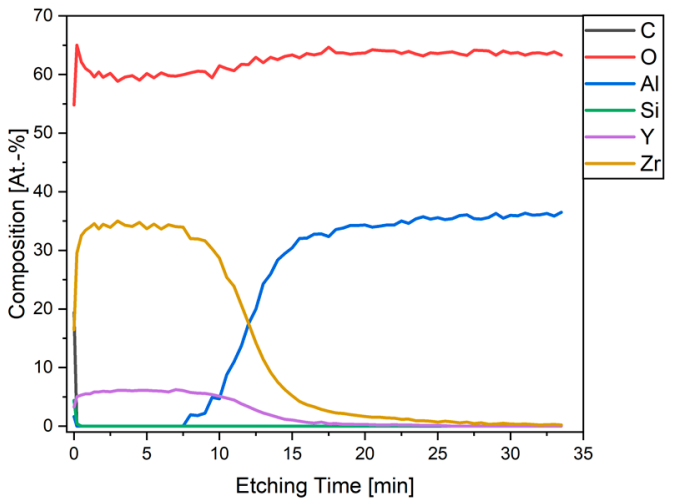

(b)

Figure 6. (a) XPS surface survey of the RF-oxide_as-sputtered sample and (b) depth-profile of the RF-oxide_1200.

\subsection{Oxygen Sensors}

The YSZ films produced by the three different sputtering techniques (DC-metallic, DC-reactive, and RF-oxide) were then used as a solid-state electrolyte in amperometric oxygen sensors and compared according to their oxygen sensing properties. The sensor performances were evaluated by the respective characteristic curves shown in Figure 7. The characteristic curves display the measured current during the increasing $p_{\mathrm{O}_{2}}$ steps of the cyclic test described previously. The current or signal of the RE_600 and RF_600 sensors increased proportionally with the $p_{\mathrm{O}_{2}}$ throughout the measured range. The current of the ME_600 sensor at $p_{\mathrm{O}_{2}}<2 \times 10^{-4} \mathrm{mbar}$ did not increase significantly. This phenomenon persisted even after annealing at $1200{ }^{\circ} \mathrm{C}$. The lack of sensitivity of the metallic-sputtered sensors could be related to the yttria surface segregation. As stated by Park et al., the yttrium-rich surface obtained after annealing at high temperatures can result in a higher oxygen incorporation barrier and the reduction of the concentration of mobile oxide ion vacancies at the surface [32]. This could be crucial at low partial pressures, where few oxygen molecules reach the sensing electrode. Electronic conduction in the metallicsputtered YSZ electrolyte could be another possible cause for the low sensitivity at low oxygen partial pressures as suggested by Sridhar [33]. The electronic conductivity could be enhanced by the presence of silver impurities, as found by the XPS analysis. The degradation of the platinum electrode and its effect on the sensor current was not assessed and is out of the scope this work.

An additional parameter to evaluate the sensor performance is the response time. In this work, the response time is defined as the time a sensor needs to achieve $90 \%$ of its steady-state current for a defined $p_{\mathrm{O}_{2}}$. The sensor was considered to be in a steady state during the last $30 \mathrm{~s}$ of a $p_{\mathrm{O}_{2}}$ increasing step. The response time shown in Figure 8 corresponds to the second cycle and to a $p_{\mathrm{O}_{2}}$ of $1 \times 10^{-4}$ mbar. Even though the sensors using the DC-reactive and RF-oxide sputtered thin films exhibited similar characteristic curves, the RF-oxide sensors displayed the shortest response time. While the response time of the DC-reactive and RF-oxide sensors deteriorate after annealing above $800^{\circ} \mathrm{C}$, the DC-metallic sensors response time improved after thermal annealing at $1000^{\circ} \mathrm{C}$. At this temperature, the largest increase in grain growth occurs as it can be seen in Table 2. This was also confirmed by the AFM grain growth evolution shown in Figure 5. An increase in grain size could lead to fewer grain boundaries, where the ionic conductivity can be lower compared to the bulk [32]. 


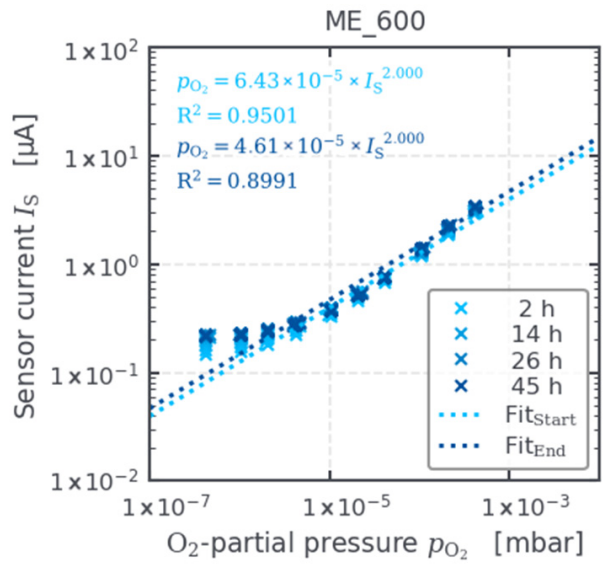

(a)

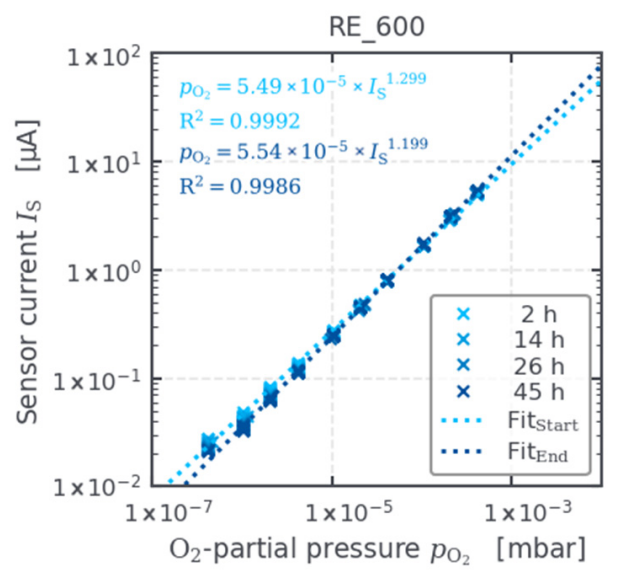

(b)

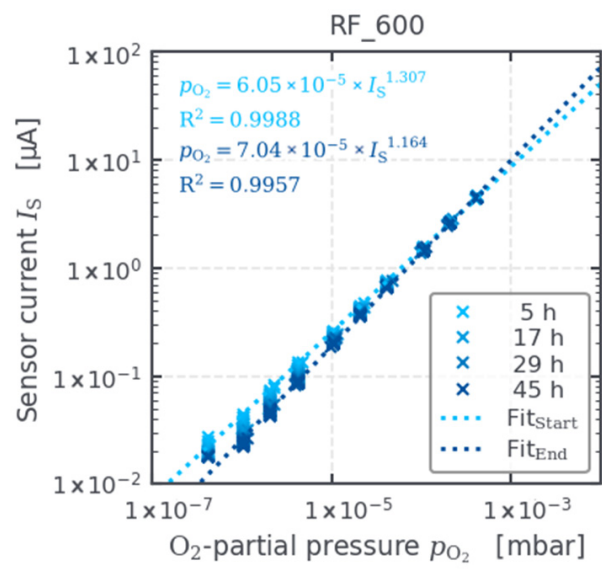

(c)

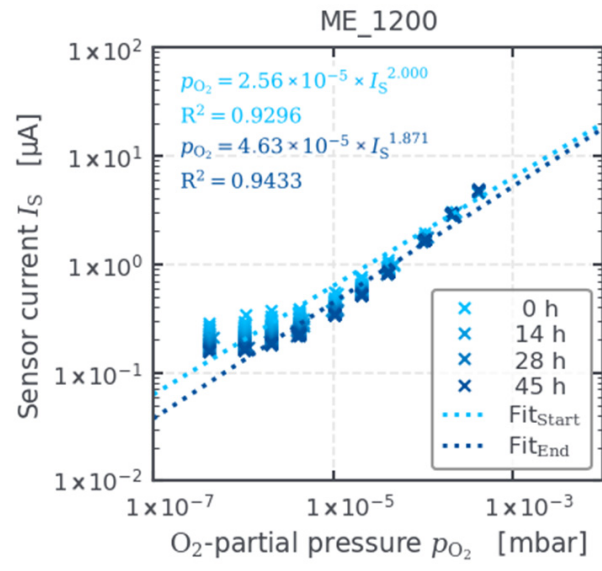

(d)

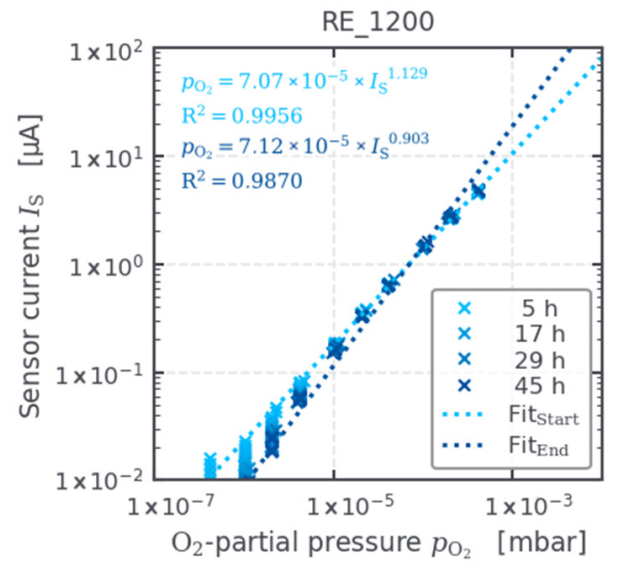

(e)

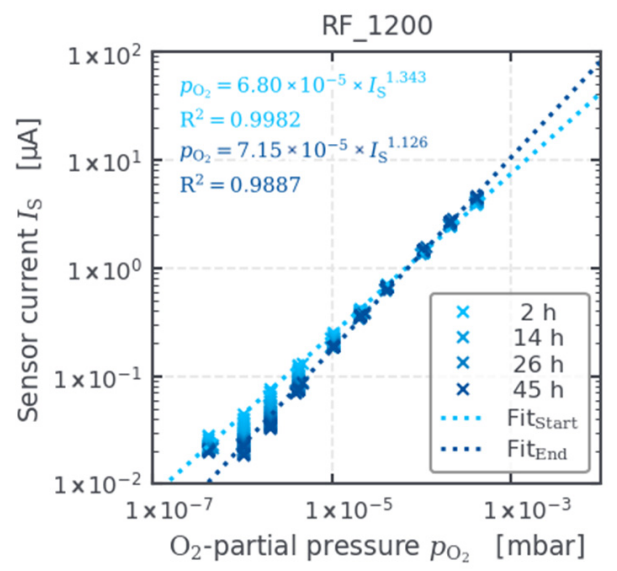

(f)

Figure 7. Characteristic curves of the sensors manufactured using the YSZ thin films as solid-state electrolyte after the thermal annealing treatment at 600 and $1200{ }^{\circ} \mathrm{C}:(\mathbf{a}, \mathbf{d})$ DC-metallic; (b,e) DCreactive; and (c,f) RF-oxide. The Y-axes are presented in logarithmic scale. The current drift over the time is represented by the (blue) color scale. 


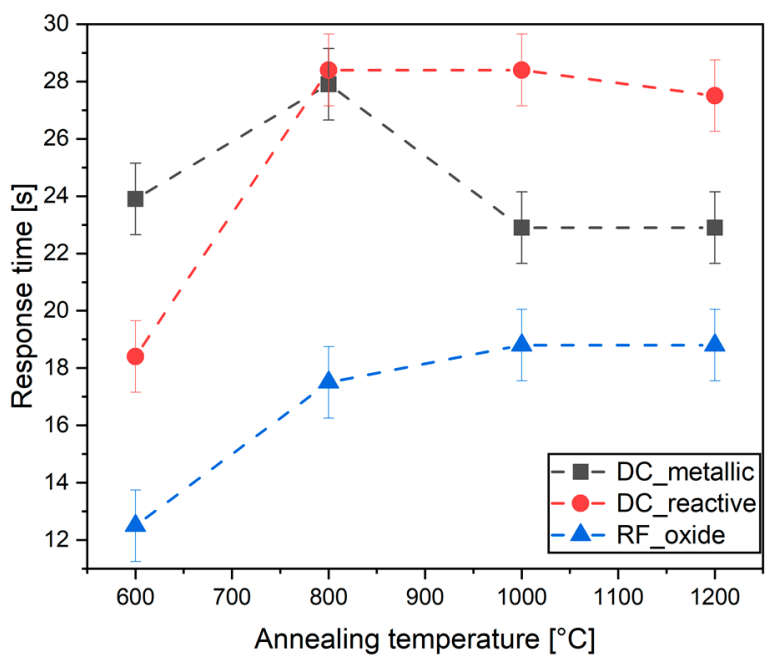

Figure 8. Sensor response time at a $p_{\mathrm{O}_{2}}=1 \times 10^{-4}$ mbar using the annealed YSZ thin films as solid-state electrolyte.

As illustrated by the results which are depicted in Figures 7 and 8, the thermal annealing process at high temperatures $\left(<1000{ }^{\circ} \mathrm{C}\right)$ was detrimental for the sensor performance in most of the cases. Specifically, the response time became slower at low oxygen partial pressures, while a current loss after each cycle was observed in the characteristic curves of the reactive and RF-sputtered films. The surface diffusion of aluminum and silicon atoms on the electrolyte films measured by XPS could explain this. As reported in literature, the segregation of yttrium or impurities to the surface or to the grain boundaries can create a space charge layer (SCL) in which positive charges are accumulated and the oxygen vacancies in the adjacent layers are depleted [34-37]. Thus, the formation of space charge layers hinders the flow of oxygen ions from grain to grain [38]. This charge build-up can become relevant at low $p_{\mathrm{O}_{2}}$, where few oxygen ions flow across the electrolyte.

Nevertheless, annealing can be beneficial for the ionic conductivity of solid-state electrolyte films. Sputtered films suffer from compressive stress due to the ballistic nature of their film growth. As stated by Yeh, thermal annealing in air at $800{ }^{\circ} \mathrm{C}$ can improve the ionic conductivity of sputtered YSZ thin films by the relaxation of its residual stress [39]. Similarly, thermal annealing can induce tensile strain, which can enhance the oxygen transport [40]. Therefore, a trade-off between strain relaxation and impurities segregation needs to be achieved when performing a post-deposition thermal treatment on thin films, such as yttria-stabilized zirconia, which are to be used as solid-state electrolyte. Understanding the role of grain boundaries on the ionic transport properties of nanocrystalline materials is of main interest nowadays as solid-state electrolytes become more relevant in applications such as batteries and fuel cells $[29,41,42]$.

\section{Conclusions}

The feasibility of using magnetron sputtering to manufacture thin film sensors was assessed in this work. Three different sputtering techniques were used to produce YSZ thin films: DC-metallic, DC-reactive, and RF-oxide. The thin films were then annealed in air from 600 to $1200^{\circ} \mathrm{C}$. As the XRD and AFM measurements revealed, after the annealing process at $600{ }^{\circ} \mathrm{C}$, all samples displayed the cubic zirconia phase. After thermal annealing above $1000{ }^{\circ} \mathrm{C}$, defined grains were observed in the SEM and AFM images. The XPS measurements confirmed the diffusion of impurities ( $\mathrm{Al}$ and $\mathrm{Si}$ ) to the surface of the RFsputtered YSZ films after annealing above $1000^{\circ} \mathrm{C}$, whereas yttria surface enrichment was observed in the metallic-sputtered sample after the heat treatment at $600{ }^{\circ} \mathrm{C}$.

The YSZ thin films were used to produce amperometric oxygen sensor prototypes for vacuum applications. Both the DC-reactive and RF-oxide sputtered YSZ films displayed a high correlation between the sensor current and the analyzed oxygen partial pressures. 
Meanwhile, the metallic-sputtered electrolyte suffered from electronic conduction at low oxygen partial pressures. In general, the sensors manufactured in this work did not display a current stagnation or reach a plateau even at higher oxygen partial pressures $\left(p_{\mathrm{O}_{2}}>1 \times 10^{-4} \mathrm{mbar}\right)$. This suggests the presented sensor setup might be also suitable for higher oxygen partial pressures.

By using reactive sputtering to deposit substoichiometric oxides, a higher deposition rate and lower costs can be achieved. Yet, an annealing step is needed to achieve fully oxidized films. Meanwhile, the RF-sputtered fully oxide films exhibited the desired cubic crystal structure directly after deposition. Additionally, the sensors using these films as electrolyte displayed the shortest response time. However, RF-sputtering had the lowest deposition rate between the three techniques assessed in this work. As suggested in the literature, annealing can be beneficial for the oxygen transport properties of the YSZ films. Nevertheless, as shown in this article, high temperatures above $1000{ }^{\circ} \mathrm{C}$ may have detrimental effects on the ionic conductivity of the YSZ thin film due to the surface segregation of impurities.

Author Contributions: Conceptualization, supervision, and writing, E.P.A. Data curation and writing, P.G. Investigation and analysis, X.W. Review, project administration, and advice, T.K. and S.F. All authors have read and agreed to the published version of the manuscript.

Funding: This research was funded by the German Federal Ministry for Economic affairs and energy (BMWI) under the joint research project "Oxycontrol", project number 03ET1519A.

Institutional Review Board Statement: Not applicable.

Informed Consent Statement: Not applicable.

Data Availability Statement: Not applicable.

Acknowledgments: The authors thank Sophie Gledhill and Shankar Bogati for the proofreading and advice for this article. Likewise, the authors thankfully acknowledge Markus Ohnemus for the GIXRD measurements, and Laura Stevens and Oliver Höhn for the AFM measurements.

Conflicts of Interest: The authors declare no conflict of interest.

\section{References}

1. Lange, A.; Braun, R.; Schulz, U. PVD thermal barrier coating systems for Mo-Si-B alloys. Mater. High Temp. 2018, 35, 195-203. [CrossRef]

2. Keyvani, A. Microstructural stability oxidation and hot corrosion resistance of nanostructured $\mathrm{Al}_{2} \mathrm{O}_{3} / \mathrm{YSZ}_{\text {composite compared }}$ to conventional YSZ TBC coatings. J. Alloys Compd. 2015, 623, 229-237. [CrossRef]

3. Budinovskii, S.A.; Chubarov, D.A.; Matveev, P.V.; Smirnov, A.A. Deposition and Properties of the Ceramic TBC Layer Prepared by Magnetron Sputtering. Russ. Metall. 2019, 2019, 1280-1284. [CrossRef]

4. Jo, S.; Sharma, B.; Park, D.-H.; Myung, J. Materials and nano-structural processes for use in solid oxide fuel cells: A review. J. Korean Ceram. Soc. 2020, 57, 135-151. [CrossRef]

5. Bae, J.; Chang, I.; Kang, S.; Hong, S.; Cha, S.W.; Kim, Y.B. Post-annealing of thin-film yttria stabilized zirconia electrolytes for anode-supported low-temperature solid oxide fuel cells. J. Nanosci. Nanotechnol. 2014, 14, 9294-9299. [CrossRef]

6. Jang, D.Y.; Kim, H.K.; Kim, J.W.; Bae, K.; Schlupp, M.V.; Park, S.W.; Prestat, M.; Shim, J.H. Low-temperature performance of yttria-stabilized zirconia prepared by atomic layer deposition. J. Power Sources 2015, 274, 611-618. [CrossRef]

7. Nurhamizah, A.R.; Ibrahim, Z.; Muhammad, R.; Wahab, Y.; Sakrani, S. Effect of Annealing Temperature on Platinum/YSZ Thin Film Fabricated Using RF and DC Magnetron Sputtering. In Solid State Phenomena; Trans Tech Publications Ltd.: Stafa-Zurich, Switzerland, 2017; Volume 268, pp. 229-233. [CrossRef]

8. Liu, Y.; Parisi, J.; Sun, X.; Lei, Y. Solid-state gas sensors for high temperature applications-A review. J. Mater. Chem. A 2014, 2, 9919-9943. [CrossRef]

9. Akasaka, S. Thin film YSZ-based limiting current-type oxygen and humidity sensor on thermally oxidized silicon substrates. Sens. Actuators B Chem. 2016, 236, 499-505. [CrossRef]

10. Xu, L.; Dai, Z.; Duan, G.; Guo, L.; Wang, Y.; Zhou, H.; Liu, Y.; Cai, W.; Wang, Y.; Li, T. Micro/Nano gas sensors: A new strategy towards in-situ wafer-level fabrication of high-performance gas sensing chips. Sci. Rep. 2015, 5, 10507. [CrossRef] [PubMed]

11. Butz, B.; Störmer, H.; Gerthsen, D.; Bockmeyer, M.; Krüger, R.; Ivers-Tiffée, E.; Luysberg, M. Microstructure of Nanocrystalline Yttria-Doped Zirconia Thin Films Obtained by Sol-Gel Processing. J. Am. Ceram. Soc. 2008, 91, 2281-2289. [CrossRef] 
12. Yamada, T.; Okuda, R.; Hirakoso, H.; Kozuka, H. Sol-gel preparation of yttria-stabilized zirconia thin films and transfer to polycarbonate substrates. J. Sol.-Gel. Sci. Technol. 2019, 92, 554-561. [CrossRef]

13. Schlupp, M.V.F.; Evans, A.; Martynczuk, J.; Prestat, M. Micro-Solid Oxide Fuel Cell Membranes Prepared by Aerosol-Assisted Chemical Vapor Deposition. Adv. Energy Mater. 2014, 4, 1301383. [CrossRef]

14. Solovyev, A. Comparison of Sputter-deposited Single and Multilayer Electrolytes based on Gadolinia-doped Ceria and Yttriastabilized Zirconia for Solid Oxide Fuel Cells. Int. J. Electrochem. Sci. 2020, 231-240. [CrossRef]

15. Peters, C.; Weber, A.; Butz, B.; Gerthsen, D.; Ivers-Tiffée, E. Grain-Size Effects in YSZ Thin-Film Electrolytes. J. Am. Ceram. Soc. 2009, 92, 2017-2024. [CrossRef]

16. Mengucci, P.; Barucca, G.; Caricato, A.P.; Di Cristoforo, A.; Leggieri, G.; Luches, A.; Majnia, G. Effects of annealing on the microstructure of yttria-stabilised zirconia thin films deposited by laser ablation. Thin Solid Film. 2005, 478, 125-131. [CrossRef]

17. Briois, P.; Gourba, E.; Billard, A.; Ringuedé, A.; Cassir, M. Microstructure-Electrical properties relationship of YSZ thin films reactively sputter-deposited at different pressures. Ionics 2001, 11, 301-305. [CrossRef]

18. Paek, J.Y.; Chang, I.; Park, J.H.; Ji, S.; Cha, S.W. A study on properties of yttrium-stabilized zirconia thin films fabricated by different deposition techniques. Renew. Energy 2014, 65, 202-206. [CrossRef]

19. López-Gándara, C.; Ramos, F.M.; Cirera, A. YSZ-Based Oxygen Sensors and the Use of Nanomaterials: A Review from Classical Models to Current Trends. J. Sens. 2009, 2009, 1-15. [CrossRef]

20. Schwarzwaelder, C. Inkjet Method for the Development of Solid State Electrolyte Sensors for Space Applications; University of Stuttgart: Stuttgart, Germany, 2016.

21. Götsch, T.; Wallisch, W.; Stöger-Pollach, M.; Klötzer, B.; Penner, S. From zirconia to yttria: Sampling the YSZ phase diagram using sputter-deposited thin films. AIP Adv. 2016, 6, 25119. [CrossRef]

22. Rusli, N.A.; Muhammad, R.; Ghoshal, S.K.; Nur, H.; Nayan, N. Annealing temperature induced improved crystallinity of YSZ thin film. Mater. Res. Express 2020, 7, 56406. [CrossRef]

23. Rusli, N.A.; Muhammad, R.; Ghoshal, S.K.; Nur, H.; Nayan, N.; Jaafar, S.N. Bias voltage dependent structure and morphology evolution of magnetron sputtered YSZ thin film: A basic insight. Mater. Res. Express 2019, 6, 106414. [CrossRef]

24. Smeacetto, F.; Salvo, M.; Ajitdoss, L.C.; Perero, S.; Moskalewicz, T.; Boldrini, S.; Doubova, L.; Ferraris, M. Yttria-stabilized zirconia thin film electrolyte produced by RF sputtering for solid oxide fuel cell applications. Mater. Lett. 2010, 64, 2450-2453. [CrossRef]

25. Kastelik, R. Messsysteme für Sauerstoff-Sensoren auf Basis von Festkörperelektrolyten; University of Stuttgart: Stuttgart, Germany, 2020.

26. Patel, P.; Hull, T.R.; McCabe, R.W.; Flath, D.; Grasmeder, J.; Percy, M. Mechanism of thermal decomposition of poly(ether ether ketone) (PEEK) from a review of decomposition studies. Polym. Degrad. Stab. 2010, 95, 709-718. [CrossRef]

27. Zhang, J.; Huang, X.; Zhang, H.; Xue, Q.; Xu, H.; Wang, L.; Feng, Z. The effect of powder grain size on the microstructure and electrical properties of $8 \mathrm{~mol} \% \mathrm{Y}_{2} \mathrm{O}_{3}$-stabilized $\mathrm{ZrO}_{2}$. RSC Adv. 2017, 7, 39153-39159. [CrossRef]

28. Subramaniam, K.M.; Rajeswara Rao, L.L.; Jampana, N. Investigation of Annealing Induced Yttria Segregation in Sputtered Yttria-Stabilized Zirconia Thin Films. J. Am. Ceram. Soc. 2015, 98, 3389-3397. [CrossRef]

29. An, J.; Bae, J.; Hong, S.; Koo, B.; Kim, Y.-B.; Gür, T.M.; Prinz, F.B. Grain boundary blocking of ionic conductivity in nanocrystalline yttria-doped ceria thin films. Scr. Mater. 2015, 104, 45-48. [CrossRef]

30. Vonk, V.; Khorshidi, N.; Stierle, A.; Dosch, H. Atomic structure and composition of the yttria-stabilized zirconia (111) surface. Surf. Sci. 2013, 612, 69-76. [CrossRef]

31. Ridder, M.D.; Welzenis, R.G.V.; Gon, A.W.D.V.D.; Brongersma, H.H.; Wulff, S.; Chu, W.-F.; Weppner, W. Subsurface segregation of yttria in yttria stabilized zirconia. J. Appl. Phys. 2002, 92, 3056-3064. [CrossRef]

32. Park, J.S.; An, J.; Lee, M.H.; Fritz, B.P.; Lee, W. Effects of surface chemistry and microstructure of electrolyte on oxygen reduction kinetics of solid oxide fuel cells. J. Power Sources 2015, 295, 74-78. [CrossRef]

33. Sridhar, K.; Blanchard, J. Electronic conduction in low oxygen partial pressure measurements using an amperometric zirconia oxygen sensor. Sens. Actuators B 1999, 59, 60-67. [CrossRef]

34. Durá, O.J.; La López de Torre, M.A.; Vázquez, L.; Chaboy, J.; Boada, R.; Rivera-Calzada, A.; Santamaria, J.; Leon, C. Ionic conductivity of nanocrystalline yttria-stabilized zirconia: Grain boundary and size effects. Phys. Rev. B 2010, 81. [CrossRef]

35. Guo, X.; Maier, J. Grain Boundary Blocking Effect in Zirconia: A Schottky Barrier Analysis. J. Electrochem. Soc. 2001, 148, E121-E126. [CrossRef]

36. Guo, X.; Waser, R. Electrical properties of the grain boundaries of oxygen ion conductors: Acceptor-doped zirconia and ceria. Prog. Mater. Sci. 2006, 51, 151-210. [CrossRef]

37. Lee, H.B.; Prinz, F.B.; Cai, W. Atomistic simulations of grain boundary segregation in nanocrystalline yttria-stabilized zirconia and gadolinia-doped ceria solid oxide electrolytes. Acta Mater. 2013, 61, 3872-3887. [CrossRef]

38. Schlupp, M.V.F.; Scherrer, B.; Ma, H.; Grolig, J.G.; Martynczuk, J.; Prestat, M.; Gauckler, L.J. Influence of microstructure on the cross-plane oxygen ion conductivity of yttria stabilized zirconia thin films. Phys. Status Solidi A 2012, 209, 1414-1422. [CrossRef]

39. Yeh, T.-H.; Lin, R.-D.; Cherng, J.-S. Significantly enhanced ionic conductivity of yttria-stabilized zirconia polycrystalline nano-film by thermal annealing. Thin Solid Film 2013, 544, 148-151. [CrossRef]

40. Mills, E.M.; Kleine-Boymann, M.; Janek, J.; Yang, H.; Browning, N.D.; Takamura, Y.; Kim, S. YSZ thin films with minimized grain boundary resistivity. Phys. Chem. Chem. Phys. 2016, 18, 10486-10491. [CrossRef] [PubMed] 
41. Guo, X.; Sigle, W.; Maier, J. Blocking Grain Boundaries in Yttria-Doped and Undoped Ceria Ceramics of High Purity. J. Am. Ceram. Soc. 2003, 86, 77-87. [CrossRef]

42. Bae, J.W.; Park, J.Y.; Hwang, S.W.; Yeom, G.Y.; Kim, K.D.; Cho, Y.A.; Jeon, J.S.; Choi, D. Characterization of Yttria-Stabilized Zirconia Thin Films Prepared by Radio Frequency Magnetron Sputtering for a Combustion Control Oxygen Sensor. J. Electrochem. Soc. 2000, 147, 2380-2384. [CrossRef] 